\title{
Comparison of Epidural Analgesia vs Continuous Transversus Abdominis Plane Analgesia for Post-Operative Pain Relief in Patients Undergoing Lower Abdominal Surgery
}

\author{
Ramesh Kumar N. ${ }^{1}$
}

\author{
${ }^{1}$ Department of Anaesthesiology, Sambhram Medical College, KGF, Kolar, Karnataka, India.
}

\section{ABSTRACT}

\section{BACKGROUND}

Regional Anaesthesia for post-operative analgesia has become an important tool in the anaesthetist's arsenal. Epidural analgesia has become a standard of care for abdominal surgeries; however, it has its own complications. Further, many patients cannot benefit from it when contraindicated. Transversus Abdominis Plane (TAP) block is a relatively new technique of regional anaesthesia which has the potential to be an alternative to Epidural analgesia for abdominal surgeries. However, it remains a yet poorly explored technique. This is more so in the case of continuous TAP Blocks by means of a catheter. Few studies have been done comparing it with epidural analgesia.

\section{METHODS}

72 patients undergoing lower abdominal surgery under spinal anaesthesia were randomized to receive epidural anaesthesia with $10 \mathrm{ml} 0.125 \%$ Bupivacaine $8^{\text {th }}$ hourly or TAP Block with $20 \mathrm{ml} 0.125 \%$ Bupivacaine on each side $8^{\text {th }}$ hourly. VAS scores at rest and on coughing, consumption of Paracetamol (first rescue analgesic) and consumption of Tramadol (second rescue analgesic) were recorded along with heart rate, blood pressure and respiratory rate.

\section{RESULTS}

VAS scores at rest were comparable between the groups in the first 16 hours. However, at 24 and 48 hours, the TAP Block group had significantly higher VAS scores at rest. Similar results were seen for the VAS score on coughing. The first 8 hours were comparable between the groups, beyond which, VAS scores were significantly higher in the TAP Block Group. Analgesic consumption reflected the same with paracetamol (first analgesic) consumption being comparable throughout the study, however, the consumption of tramadol (second rescue analgesic) was significantly higher in the TAP block group at the end of 24 as well as 48 hours.

\section{CONCLUSIONS}

The findings suggest that Analgesia with Epidural as well as with continuous TAP Block at $8^{\text {th }}$ hourly bolus dosing of $0.125 \%$ Bupivacaine in patients undergoing lower abdominal surgeries is comparable in the first 8 to 16 hours. However, the quality of analgesia provided by the TAP Block catheter is inferior to that provided by epidural catheters beyond 24 hours post-operative period.

\section{KEY WORDS}

Regional Anaesthesia, Post-Operative Analgesia, Transversus Abdominis Plane Block, Epidural Analgesia, Bupivacaine, Catheter-Based Techniques
Corresponding Author:

Dr. Ramesh Kumar N., A-1, No. 25, Ashirwad Residency, RMV $2^{\text {nd }}$ Stage, Lottegollahalli, New Ramaiah Compound, Bangaluru-94, Karnataka, India. E-mail: rameshnareppa@gmail.com

DOI: $10.14260 / \mathrm{jemds} / 2020 / 139$

Financial or Other Competing Interests: None.

How to Cite This Article:

Kumar RK. Comparison of epidural analgesia vs continuous transversus abdominis plane analgesia for postoperative pain relief in patients undergoing lower abdominal surgery. J. Evolution Med. Dent. Sci. 2020;9(09):634640, DOI: 10.14260/jemds/2020/139

Submission 05-08-2019,

Peer Review 02-02-2020,

Acceptance 11-02-2020,

Published 02-03-2020.

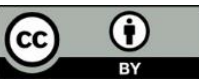




\section{BACKGROUND}

Control of post-operative pain is imperative for patient comfort, early mobilization and faster recovery.(1) Specifically, good post-operative pain management has been shown to be effective in reducing peri-operative morbidity associated with acute coronary events and thrombotic events in high risk patients. (2) At the same time, it has been an endeavour to reduce peri-operative opioid consumption and its associated complications. In this respect, an effective multimodal strategy which affords best control of postoperative pain is very important. Increasingly, Regional Techniques are gaining popularity as a part of multimodal post-operative analgesic regimen. Regional Anaesthesia has been shown to reduce the incidence of post-operative nausea and vomiting while also providing benefits that go even beyond patient comfort. Epidural Analgesia is a time tested technique for post-operative analgesia. It has proven efficacy and use of epidural catheters for post-operative analgesia is a norm at many centres. However, the epidural technique comes with its own risk of complications. Also, there are many situations where it would be contraindicated to use the epidural technique. Thus, an equally effective alternative regional anaesthetic technique would be useful in such situations.

The Transversus Abdominis Plane (TAP) Block and TAP catheter based continuous blocks are relatively new techniques whose efficacy has been well documented in the scientific literature (3), (4), (5), (6) They are regional anaesthesia techniques which provide analgesia to the skin and muscles of the anterior abdominal wall. (7) It was first described just about a decade ago and has undergone several modifications which in turn have expanded its scope of application for an increasing range of surgical procedures. (8) Their advantage over epidural technique lies in the fact that it does not cause hemodynamic instability. Another advantage is that they can be used in patients with mild platelet or coagulation abnormalities where neuraxial techniques would be contraindicated. Despite a low risk of complications and a high success rate, it is an underutilized technique. (9)

\section{METHODS}

After obtaining ethical clearance certificate from the institution's ethics committee, a prospective randomized comparative study was conducted among 72 patients, who were to undergo elective lower abdominal surgeries, admitted to Sri Devaraj Urs Medical College Hospital from September 2012 to Aug 2013.

\section{Sample Size}

In a previous study by Vandriessche et al A VAS score of 4.8 $\mathrm{cm}$ (SD: $1.8 \mathrm{~cm}$ ) for TAP block group and VAS score of $3.2 \mathrm{~cm}$ (SD: $2.1 \mathrm{~cm}$ ) for epidural group was observed. Assuming similar results, it was calculated that to obtain a power of $80 \%$ within a confidence interval of $95 \%$, a minimum of 30 patients were required in each of the two groups. Thus, a total of 60 patients were required at the least. An additional $5 \%$ (6 in each group) were taken to account for drop-outs from the study.

\section{Inclusion Criteria}

1. Lower Abdominal Surgeries under Spinal Anesthesia.

2. American Society of Anesthesiologists (ASA) Physical Status (PS) I and II.

3. $18-75$ years age.

\section{Exclusion Criteria}

1. Patient refusal for epidural or TAP catheter placement.

2. $\mathrm{BMI}>30$.

3. Coagulation disorders.

4. Infection at the site of injection and insertion of needle.

5. Use of Opioids or Alpha-2 agonists for sedation, premedication or post-operative analgesia (except for Tramadol)

6. Catheter dislodgement at any time before the end of the 48 hours post-operative.

Written informed consent was taken. A computer generated random number table was used to randomize the patients in two groups. In both groups, patients were Premedicated with per oral tablet Ranitidine $150 \mathrm{mg}$ and tablet Ondansetron $8 \mathrm{mg}$. All the patients underwent lower abdominal surgery under spinal anaesthesia with $2-3 \mathrm{ml}$ $0.5 \%$ Bupivacaine and $60-90$ micrograms of Buprenorphine - as per the attending anaesthetist's discretion. Intraoperative sedation, if required, was provided with injection Midazolam IV, titrated to effect.

Patients in Group 'E' had a lumbar epidural catheter (22G, Multi-orifice) placed at L1 - L2 or L2 - L3 (best available) intervertebral space. The catheter was placed with the patient seated, before giving the spinal anaesthetic. "Loss of Resistance to Air" technique with 18G Tuohy needle (Perifix $^{\mathrm{TM}}$, B. Braun Melsungen) was used and $5 \mathrm{~cm}$ of the catheter was left in-situ. A test dose of $3 \mathrm{ml}$ solution of $2 \%$ Lidocaine with $5 \mathrm{mcg} / \mathrm{ml}$ adrenaline was given to rule out intra-thecal and intra-vascular placement of the catheter. However, the epidural catheter was not activated till at the end of the surgery.

Patients in Group ' $\mathrm{T}$ ' received bilateral TAP block at the end of the surgery. The Block was given using O'Donnel's "Two 'pop' technique" with a 16G IV cannula (Venflon ${ }^{\text {TM }}$, Becton and Dickinson) whose stylet had been blunted at the tip by striking it over a sterile surface. After injecting the local anaesthetic solution, the stylet was removed and the $16 \mathrm{G}$ cannula was left in situ. The cannula was secured in place using waterproof "Duropore ${ }^{\mathrm{TM} \text { " }}$ plaster (3M Healthcare). In case the patient experienced pain during the surgery, they were considered to have been dropped out of the study as an alternative technique to spinal anaesthesia would have to be used. Patients in group "E" had the epidural activated with $0.25 \%$ Bupivacaine while patients in Group " $\mathrm{T}$ " were induced to general anaesthesia.

At the end of the surgery, Group E received $10 \mathrm{ml}$ of $0.125 \%$ Bupivacaine $0.5 \%$ Anawin $^{\mathrm{TM}}$, Neon Laboratories diluted with Normal Saline) in the epidural catheter while group $\mathrm{T}$ received $20 \mathrm{ml}$ of $0.125 \%$ Bupivacaine on each side (during placement of the block). Subsequent top-ups of the same dosage were given at eighth hourly intervals. IV Paracetamol 1 gram and IV Tramadol $50 \mathrm{mg}$ were prescribed as the first and second rescue analgesics, respectively. Patients were assessed for pain at 8, 16, 24- and 48-hours post-operative. 
Assessment of pain was done using-

1. VAS score for pain at rest.

2. VAS score for pain on coughing.

3. Consumption of rescue analgesic.

Additionally, blood pressure, heart rate and respiratory rate were also recorded when top-ups were given, as a part of institutional protocol.

\section{Statistical Methods}

Owing to the discrete nature of the measured data along with divisibility into a small number of categories made it appropriate to use non-parametric analysis. Thus the Chisquare test was used to obtain the results. In doing so, it was imperative that each category should not have less than $20 \%$ of the total number. Wherever this was violated that category was clubbed with the next higher or next lower category, as appropriate.

For ease of calculation, VAS scores of the patient were grouped into 4 categories-

1. $\mathrm{Nil}=$ VAS score 0

2. Mild $=$ VAS score $>0-3$

3. Moderate $=$ VAS score $>3-6$

4. Severe $=$ VAS score $>6-10$

The descriptive statistics for the continuous independent variables of patient data was analysed using ' $\mathrm{T}$ ' test.

Assumptions made on data-

1. The variables are normally distributed.

2. Samples drawn from the population are random.

3. The samples taken are unrelated.

The statistical software used was Statistical Package for Social Sciences (SPSS) version 20, 2011 (IBM).

\section{RESULTS}

Out of the 72 patients selected, 69 completed the trial, 36 in the epidural group and 33 in the TAP block group. In two of the patients in the TAP block group, the case had to be converted to General Anaesthesia as the anaesthesia was inadequate while in one of the patients, the catheter became dislodged after the patient had been shifted back to the ward. Data was compared for demographics, VAS score at 8, 16, 24 and 48 hours. Consumption of Paracetamol in the first 24 hours and total Paracetamol consumption were also compared. A similar comparison was made for Tramadol consumption in the first 24 hours as well as total consumption.

\section{Demographic Data}

No statistically significant difference was found in the age, sex, ASA Physical Status, weight, height and BMI of the patients. Also, the baseline pulse rate, respiratory rate and mean arterial pressure were no different between the two groups.

\begin{tabular}{|c|c|c|c|c|}
\hline \multicolumn{2}{|c|}{} & \multicolumn{2}{c|}{ Gender } & \multirow{2}{*}{ Total } \\
\cline { 3 - 5 } \multicolumn{2}{|c|}{} & Male & Female & \\
\hline \multirow{2}{*}{ Epidural } & Count & 7 & 29 & 36 \\
\cline { 2 - 5 } & $\%$ & $19.4 \%$ & $80.6 \%$ & $100.0 \%$ \\
\hline \multirow{2}{*}{ TAP } & Count & 3 & 30 & 33 \\
\cline { 2 - 5 } & $\%$ & $9.1 \%$ & $90.9 \%$ & $100.0 \%$ \\
\hline \multirow{2}{*}{ Total } & Count & 10 & 59 & 69 \\
\cline { 2 - 4 } & $\%$ & $14.5 \%$ & $85.5 \%$ & $100.0 \%$ \\
\hline \multicolumn{3}{|c|}{ Table 1. Sex Distribution in Both the Groups } \\
\hline \multicolumn{3}{|c|}{ Degrees of freedom: 1, 'p' value: 0.222. }
\end{tabular}

\begin{tabular}{|c|c|c|c|c|c|}
\hline & & $\mathbf{N}$ & Mean & $\begin{array}{c}\text { Std. } \\
\text { Deviation }\end{array}$ & \begin{tabular}{|c|}
$\begin{array}{c}\text { Std. Error } \\
\text { Mean }\end{array}$ \\
\end{tabular} \\
\hline \multirow{2}{*}{ Age } & Epidural & 36 & 46.03 & 11.958 & 1.993 \\
\hline & TAP & 33 & 40.52 & 11.732 & 2.042 \\
\hline \multirow{2}{*}{ Weight } & Epidural & 36 & 63.50 & 6.575 & 1.096 \\
\hline & TAP & 33 & 62.03 & 6.536 & 1.138 \\
\hline \multirow{2}{*}{ Height } & Epidural & 36 & 162.11 & 5.075 & .846 \\
\hline & TAP & 33 & 160.30 & 3.610 & .628 \\
\hline \multirow{2}{*}{$\begin{array}{c}\text { Heart rate } \\
\text { baseline }\end{array}$} & Epidural & 36 & 80.94 & 7.950 & 1.325 \\
\hline & TAP & 33 & 80.48 & 6.462 & 1.125 \\
\hline \multirow{2}{*}{$\begin{array}{c}\text { Respiratory } \\
\text { Rate Baseline }\end{array}$} & Epidural & 36 & 16.72 & 2.711 & .452 \\
\hline & TAP & 33 & 16.48 & 3.163 & .551 \\
\hline \multirow{2}{*}{$\begin{array}{l}\text { systolic BP } \\
\text { Baseline }\end{array}$} & Epidural & 36 & 127.22 & 11.276 & 1.879 \\
\hline & TAP & 33 & 123.15 & 11.281 & 1.964 \\
\hline \multirow{2}{*}{$\begin{array}{l}\text { Diastolic BP } \\
\text { Baseline }\end{array}$} & Epidural & 36 & 80.61 & 6.741 & 1.124 \\
\hline & TAP & 33 & 78.36 & 6.717 & 1.169 \\
\hline
\end{tabular}

\begin{tabular}{|c|c|c|c|c|}
\hline \multicolumn{5}{|c|}{ Comparison of BMI between the Two Groups } \\
\hline & & \multicolumn{2}{|c|}{ Mean } & Std. Deviation \\
\hline \multirow{2}{*}{ BMI } & Epidural & \multicolumn{2}{|c|}{24.1320} & 1.93492 \\
\hline & TAP & \multirow{2}{*}{\multicolumn{2}{|c|}{$\begin{array}{c}24.1189 \\
\text { P value: } 0.979\end{array}$}} & 2.22066 \\
\hline \multirow{2}{*}{\multicolumn{5}{|c|}{$\begin{array}{c}\text { Degrees of freedom: } 63.79 \text { P value: } 0.979 \\
\text { Comparison of ASA Physical Status between the Groups }\end{array}$}} \\
\hline & & & & \\
\hline & & \multicolumn{2}{|c|}{ ASA_PS } & \multirow{2}{*}{ Total } \\
\hline & & ASA PS 1 & ASA PS 2 & \\
\hline \multirow{2}{*}{ Epidural } & Count & 23 & 13 & 36 \\
\hline & $\%$ & $63.9 \%$ & $36.1 \%$ & $100.0 \%$ \\
\hline \multirow{2}{*}{ Total } & Count & 43 & 26 & 69 \\
\hline & $\%$ & $62.3 \%$ & $37.7 \%$ & $100.0 \%$ \\
\hline \multicolumn{5}{|c|}{ Degrees of freedom: 1 P value: 0.779} \\
\hline & $\begin{array}{c}\text { arisons } \\
\text { betwe }\end{array}$ & $\begin{array}{l}\text { MI and } A \\
\text { he Group }\end{array}$ & Physi & tatus \\
\hline
\end{tabular}

\begin{tabular}{|c|c|c|c|c|c|c|}
\hline \multirow{2}{*}{ Duration } & \multirow{2}{*}{\multicolumn{2}{|c|}{ Procedure }} & \multicolumn{3}{|c|}{ VAS Score } & \multirow{3}{*}{$\begin{array}{c}\text { Total } \\
36\end{array}$} \\
\hline & & & \multirow{2}{*}{$\begin{array}{c}\text { Nil } \\
29 \\
\end{array}$} & \multirow{2}{*}{$\begin{array}{c}\text { Mild } \\
6\end{array}$} & \multirow{2}{*}{\begin{tabular}{|c|} 
Moderate \\
1
\end{tabular}} & \\
\hline \multirow{6}{*}{8 hours } & \multirow{2}{*}{ Epidural } & Count & & & & \\
\hline & & $\%$ & $80.6 \%$ & $16.7 \%$ & $2.8 \%$ & $100.0 \%$ \\
\hline & \multirow{2}{*}{ TAP } & Count & 23 & 7 & 3 & 33 \\
\hline & & $\%$ & $69.7 \%$ & $21.2 \%$ & $9.1 \%$ & $100.0 \%$ \\
\hline & \multirow{2}{*}{ Total } & Count & 52 & 13 & 4 & 69 \\
\hline & & $\%$ & $75.4 \%$ & $18.8 \%$ & $5.8 \%$ & $100.0 \%$ \\
\hline \multirow{6}{*}{16 hours } & \multirow{2}{*}{ Epidural } & Count & 30 & 5 & 1 & 36 \\
\hline & & $\%$ & $83.3 \%$ & $13.9 \%$ & $2.8 \%$ & $100.0 \%$ \\
\hline & \multirow[b]{2}{*}{ TAP } & Count & 24 & 8 & 1 & 33 \\
\hline & & $\%$ & $72.7 \%$ & $24.2 \%$ & $3.0 \%$ & $100.0 \%$ \\
\hline & \multirow{2}{*}{ Total } & Count & 54 & 13 & 2 & 69 \\
\hline & & $\%$ & $78.3 \%$ & $18.8 \%$ & $2.9 \%$ & $100.0 \%$ \\
\hline \multirow{6}{*}{24 hours } & \multirow{2}{*}{ Epidural } & Count & 33 & 2 & 1 & 36 \\
\hline & & $\%$ & $91.7 \%$ & $5.6 \%$ & $2.8 \%$ & $100.0 \%$ \\
\hline & \multirow{2}{*}{ TAP } & Count & 17 & 16 & 0 & 33 \\
\hline & & $\%$ & $51.5 \%$ & $48.5 \%$ & $0.0 \%$ & $100.0 \%$ \\
\hline & \multirow{2}{*}{ Total } & Count & 50 & 18 & 1 & 69 \\
\hline & & $\%$ & $72.5 \%$ & $26.1 \%$ & $1.4 \%$ & $100.0 \%$ \\
\hline \multirow{6}{*}{48 hours } & \multirow{2}{*}{ Epidural } & Count & 31 & - & 5 & 36 \\
\hline & & $\%$ & $86.1 \%$ & - & $13.9 \%$ & $100.0 \%$ \\
\hline & \multirow{2}{*}{ TAP } & Count & 18 & - & 15 & 33 \\
\hline & & $\%$ & $54.5 \%$ & - & $45.5 \%$ & $100.0 \%$ \\
\hline & \multirow[b]{2}{*}{ Total } & Count & 49 & - & 20 & 69 \\
\hline & & $\%$ & $71.0 \%$ & - & $29.0 \%$ & $100.0 \%$ \\
\hline & 4. $C$ & r & VAS & $a t$ & at $8 \mathrm{H}$ & \\
\hline
\end{tabular}


The distribution of VAS pain scores at rest was comparable in both the groups at the end of 8 hours postoperative. The distribution of VAS pain scores at rest was comparable in both the groups at the end of 16 hours postoperative. At the end of the first 24 hours, the epidural group was found to have better pain scores at rest with a significantly more percentage of the patients reporting a nil pain and a small percentage reporting mild to moderate pain. On the other hand, the TAP block group showed a smaller percentage of patients with nil pain and a significantly higher proportion of patients reporting mild pain. At the end of 48 hours, the epidural group still has a significantly better outcome with a higher proportion of patients reporting nil pain at rest and a lower proportion reporting mild pain at rest.

\begin{tabular}{|c|c|c|c|c|c|c|c|}
\hline \multirow{2}{*}{ Duration } & \multirow{2}{*}{\multicolumn{2}{|c|}{ Procedure }} & \multicolumn{4}{|c|}{ VAS Score on Coughing } & \multirow[b]{2}{*}{ Total } \\
\hline & & & Nil & Mild & Moderate & Severe & \\
\hline \multirow{6}{*}{8 hours } & \multirow{2}{*}{ Epidural } & \begin{tabular}{|l|} 
Count \\
\end{tabular} & 24 & 10 & 2 & 0 & 36 \\
\hline & & $\%$ & $66.7 \%$ & $27.8 \%$ & $5.6 \%$ & $0.0 \%$ & $100.0 \%$ \\
\hline & \multirow{2}{*}{ TAP } & \begin{tabular}{|l|} 
Count \\
\end{tabular} & 11 & 11 & 10 & 1 & 33 \\
\hline & & $\%$ & $33.3 \%$ & $33.3 \%$ & $30.3 \%$ & $3.0 \%$ & $100.0 \%$ \\
\hline & \multirow[b]{2}{*}{ Total } & Count & 35 & 21 & 12 & 1 & 69 \\
\hline & & $\%$ & $50.7 \%$ & $30.4 \%$ & $17.4 \%$ & $1.4 \%$ & $100.0 \%$ \\
\hline \multirow{6}{*}{16 hours } & \multirow{2}{*}{ Epidural } & Count & 20 & 13 & 2 & 1 & 36 \\
\hline & & $\%$ & $55.6 \%$ & $36.1 \%$ & $5.6 \%$ & $2.8 \%$ & $100.0 \%$ \\
\hline & \multirow{2}{*}{ TAP } & \begin{tabular}{|l|} 
Count \\
\end{tabular} & 8 & 23 & 2 & 0 & 33 \\
\hline & & $\%$ & $24.2 \%$ & $69.7 \%$ & $6.1 \%$ & $0.0 \%$ & $100.0 \%$ \\
\hline & \multirow{2}{*}{ Total } & Count & 28 & 36 & 4 & 1 & 69 \\
\hline & & $\%$ & $40.6 \%$ & $52.2 \%$ & $5.8 \%$ & $1.4 \%$ & $100.0 \%$ \\
\hline \multirow{6}{*}{24 hours } & \multirow{2}{*}{ Epidural } & \begin{tabular}{|l|} 
Count \\
\end{tabular} & 18 & 17 & 0 & 1 & 36 \\
\hline & & $\%$ & $50.0 \%$ & $47.2 \%$ & $0.0 \%$ & $2.8 \%$ & $100.0 \%$ \\
\hline & \multirow{2}{*}{ TAP } & Count & 4 & 22 & 7 & 0 & 33 \\
\hline & & $\%$ & $12.1 \%$ & $66.7 \%$ & $21.2 \%$ & $0.0 \%$ & $100.0 \%$ \\
\hline & \multirow{2}{*}{ Total } & Count & 22 & 39 & 7 & 1 & 69 \\
\hline & & $\%$ & $31.9 \%$ & $56.5 \%$ & $10.1 \%$ & $1.4 \%$ & $100.0 \%$ \\
\hline \multirow{6}{*}{48 hours } & \multirow{2}{*}{ Epidural } & \begin{tabular}{|l|} 
Count \\
\end{tabular} & 26 & 9 & 1 & - & 36 \\
\hline & & $\%$ & $72.2 \%$ & $25.0 \%$ & $2.8 \%$ & - & $100.0 \%$ \\
\hline & \multirow{2}{*}{ TAP } & Count & 10 & 18 & 5 & - & 33 \\
\hline & & $\%$ & $30.3 \%$ & $54.5 \%$ & $15.2 \%$ & - & $100.0 \%$ \\
\hline & \multirow{2}{*}{ Total } & Count & 36 & 27 & 6 & - & 69 \\
\hline & & $\%$ & $52.2 \%$ & $39.1 \%$ & $8.7 \%$ & - & $100.0 \%$ \\
\hline \multicolumn{8}{|c|}{$\begin{array}{c}\text { Table 5. Comparison of VAS Score on Coughing at } 8 \text { Hours, } \\
16 \text { hours, } 24 \text { hours, and } 48 \text { hours }\end{array}$} \\
\hline
\end{tabular}

A statistically significant difference was noted between the two groups in the distribution of pain scores in the first 8 hours post operatively. The epidural group had a higher proportion of patients with no pain on coughing and a smaller proportion with mild to severe pain on coughing as compared to the TAP block group. At 16 hours postoperative, the pain scores on coughing were significantly different. While the epidural group reported a higher proportion of patients with nil pain, the TAP block group had a higher proportion of patients reporting a mild pain. The incidence of moderate pain was comparable. At 24 hours post-operative, the results were similar to those at 16 hours post-operative. There was a slight variation with a rise in the patients reporting mild pain on coughing in the epidural group but no patient reporting moderate pain. On the other hand, there was an increase in the TAP block group patients reporting moderate pain. Overall, the epidural group patients did significantly better. On the second post-operative day, at 48 hours the epidural group was still found to be doing significantly better with a higher proportion of patients reporting no pain on coughing with a small minority complaining of mild pain while a negligible fraction of patients complaining of moderate pain. In the TAP block group, majority of the patients complained of mild pain and a sizeable number of patients even reported moderate pain.
At the end of 24 hours Consumption of Paracetamol was no different between the two groups studied. A majority of the patients were noted to have required 1-2 gm of Paracetamol for the additional analgesia. At the end of 48 hours, there was no significant difference in the Paracetamol requirements between the groups. However, all patients eventually required Paracetamol in the TAP group while some patients in the epidural group found analgesia sufficient without additional requirements.

\begin{tabular}{|c|c|c|c|c|c|c|c|}
\hline \multirow{2}{*}{ Duration } & \multirow{2}{*}{\multicolumn{2}{|c|}{ Procedure }} & \multicolumn{4}{|c|}{ Paracetamol Consumption (gm) } & \multirow[b]{2}{*}{4} \\
\hline & & & 0 & 1 & 2 & 3 & \\
\hline \multirow{6}{*}{24 hours } & \multirow{2}{*}{ Epidural } & Count & 5 & 16 & 14 & 1 & - \\
\hline & & $\%$ & $13.9 \%$ & $44.4 \%$ & $38.9 \%$ & $2.8 \%$ & - \\
\hline & \multirow{2}{*}{ TAP } & Count & 3 & 15 & 11 & 4 & - \\
\hline & & $\%$ & $9.1 \%$ & $45.5 \%$ & $33.3 \%$ & $12.1 \%$ & - \\
\hline & \multirow{2}{*}{ Total } & Count & 8 & 31 & 25 & 5 & - \\
\hline & & $\%$ & $11.6 \%$ & $44.9 \%$ & $36.2 \%$ & $7.2 \%$ & - \\
\hline \multirow{6}{*}{48 hours } & \multirow{2}{*}{ Epidural } & Count & 5 & 14 & 14 & 3 & 0 \\
\hline & & $\%$ & $13.9 \%$ & $38.9 \%$ & $38.9 \%$ & $8.3 \%$ & $0.0 \%$ \\
\hline & TAP & Count & 0 & 13 & 12 & 6 & 2 \\
\hline & & $\%$ & $0.0 \%$ & $39.4 \%$ & $36.4 \%$ & $18.2 \%$ & $6.1 \%$ \\
\hline & \multirow{2}{*}{ Total } & \begin{tabular}{|l|} 
Count \\
\end{tabular} & 5 & 27 & 26 & 9 & 2 \\
\hline & & $\%$ & $7.2 \%$ & $39.1 \%$ & $37.7 \%$ & $13.0 \%$ & $2.9 \%$ \\
\hline \multicolumn{8}{|c|}{$\begin{array}{l}\text { Table 6. Comparison of Paracetamol Consumption } \\
\text { in } 24 \text { hours and } 48 \text { hours }\end{array}$} \\
\hline
\end{tabular}

\section{DISCUSSION}

As our understanding of pain and the pathophysiology of the post-operative period has improved, the importance of adequate management of post-operative pain is increasingly being appreciated. As has been discussed, inadequate analgesia has implications which range from patient discomfort and dependence to cardiovascular and respiratory complications. In this setting, regional anaesthetic techniques have assumed great importance.

For open abdominal surgeries, epidural anaesthesia has been established to provide excellent analgesia combined with attenuation in the stress response to surgery as well as in the neurogenic contribution to inflammation. However, epidural analgesia comes with its own set of complications. By blocking thoraco-lumbar sympathetic outflow, epidural anaesthesia causes hypotension and bradycardia. Additionally, patients with mild to moderate derangements in coagulation profile or platelets are unable to reap the benefits of analgesia provided by neuraxial techniques owing to the risk of epidural haematoma. Thus it becomes necessary to explore alternative approaches to post-operative analgesia.

Since its introduction, several studies have been done on the efficacy of TAP block. Carney John, McDonnell, John G (5) et al compared single shot pre-incisional TAP block using Ropivacaine against placebo in patients undergoing abdominal hysterectomy under general anaesthesia. They found a significant reduction in post-operative VAS scores in the TAP block group vs. placebo. The 48 hour IV PCA morphine consumption was also found to be significantly lower in the TAP Block group $(27 \pm 20 \mathrm{mg})$ vs. that in the placebo group $(55 \pm 17 \mathrm{mg}, \mathrm{P}<0.001)$.

Tan, Terry T.; Teoh, Wendy H.L.; Woo, David CM et al(10) performed a similar study comparing efficacy of bilateral TAP block with Levobupivacaine against no block in women 
undergoing caesarean delivery under general anaesthesia. Though the pain scores were comparable between the groups, 24 hour morphine consumption was noted to be significantly lower $(12.3 \pm 2.6 \mathrm{mg}$ vs. $31.4 \pm 3.1 \mathrm{mg}, \mathrm{p}<0.001)$. Patient satisfaction was also much better with TAP Block ( $80 \%$ vs. $25 \%, \mathrm{p}=0.012$ ).

On the other hand, Kanazi, Ghassan E; Aouad, Marie T.; Abdallah, Faraj W. et al(11) compared subarachnoid morphine with TAP block in post caesarean section pain. They primarily evaluated the time to first request for analgesia while secondarily they looked at consumption of Tramadol (rescue analgesic) in first 12 hours. The results favoured intrathecal morphine wherein median (range) time to first request for analgesic was 8 (2-36) hours compared to $4(0.5-29)$ hours in the TAP group ( $\mathrm{p}=0.005)$. Even the Tramadol consumption was shown to be significantly lower in the Subarachnoid morphine group (0-1 vs. $0-2, \mathrm{p}=0.03$ )

However, in all these studies, the efficacy of "single shot" TAP Block was investigated. In the "single shot" TAP block, the duration of analgesia is limited by the duration of action of the drug injected and lasts for only a few hours. However, the analgesic requirements in the post-operative period can rang e from several hours to a few days. This problem can be circumvented, by placing catheters in the TAP space. Catheters enable to prolong the duration of analgesia either by using repeated intermittent boluses or by using continuous infusions of the drug.

L. Bollag, P. Richebe, C. Ortner and R. Landau(12) published a series of 5 cases where they placed bilateral ultrasound guided TAP block catheters in patients who had undergone caesarean section. They concluded that repeated local anaesthetic dosing through the TAP block catheters maybe a viable alternative or a valuable adjunct to Morphine for postoperative analgesia.

A similar case series was published by Jankovic, Zorica B.; Pollard, Stephen G. and Nachiappan, Meyyappan M.(13) wherein 7 patients were provided post-operative analgesia after renal transplant surgery using continuous local anaesthetic infusion through surgically placed TAP block catheters. The data from these patients was retrospectively compared with previous cases who had received IV PCA Morphine only. They reported $80 \%$ reduction in 24 hour morphine consumption and early cessation of IV PCA in the patients who had received TAP block.

Rao V Kadam and J B Field(14) compared continuous local anaesthetic infusion through TAP catheters against PCA Fentanyl in patients undergoing abdominal surgery. Postoperative median pain score was significantly lower in the TAP block group in the first 24 hours ( 2 vs. 6 ) as well as in the next 24 hours (2 vs. 7) with $P$ values 0.02 and 0.01 respectively. Fentanyl consumption was also lower: $78 \mathrm{mcg}$ vs. $203 \mathrm{mcg}$ on the first day and $664 \mathrm{mcg}$ vs. $1237 \mathrm{mcg}$ on the second day ( $\mathrm{p}=0.03$ and 0.01 , respectively).

In a second study, Rao V Kadam, Van Wijek RM, Moran JI and Miller $\mathrm{D}^{(15)}$ compared bilateral TAP Block local anaesthetic infusion via catheters against continuous local anaesthetic infusion via epidural in patients undergoing abdominal surgery. The authors found the post-operative VAS scores, Paracetamol and Fentanyl consumption were comparable between the two groups.
A study performed by H. Vandendriessche, Y Hoydonckx, A. Pexters and M. Van de Velde(16) compared bilateral transverses abdominis catheter infusion of Levobupivacaine against epidural infusion with Levobupivacaine with Sufentanil. On the basis of VAS scores at rest and on coughing, they concluded that the quality of analgesia was comparable in the two groups with VAS score at rest $15 \pm 12$ in the TAP block vs. $4 \pm 8$ in the epidural group while the VAS scores on coughing were $48 \pm 18$ and $32 \pm 21$, respectively.

In our study, we have compared the efficacy of bilateral TAP block catheters against epidural analgesia over 48 hours in patients undergoing lower abdominal surgery. Unlike in other studies, we have used intermittent boluses of local anaesthetic instead of continuous infusions.

Lower abdominal surgeries were chosen because the TAP block is known to anaesthetize $9^{\text {th }}$ to $12^{\text {th }}$ thoracic nerves along their course in the anterior abdominal wall. This would be adequate for infra-umbilical abdominal surgeries. To avoid the confounding effect of bilateral effect of epidural analgesia, surgeries with bilateral incisions, midline incisions or incisions crossing the midline were chosen and bilateral TAP block was used in the comparison.

Bupivacaine is a popular choice of local anaesthetic for post-operative analgesia and as such is the most common choice in our institution. Owing to its ease of availability, familiarity of use at our institution and low cost, it was used in the study. Intravenous Paracetamol and Tramadol are also commonly used analgesics at our institution in the postoperative period.

Most of the lower abdominal surgeries at our institution are performed under spinal anaesthesia. The drug used is $0.5 \%$ (heavy) Bupivacaine with Buprenorphine. Thus, the same technique was utilized for anaesthesia in the present study. To avoid the confounding effect of the profile of postoperative analgesia with General Anaesthesia and Spinal Anaesthesia, cases done under general anaesthesia were excluded from the study.

The decision to give intermittent boluses of local anaesthetic over continuous infusions was taken due to the issue of cost constraints raised by the ethics committee. Based on the same concerns of cost, commercially available regional anaesthesia catheters were eschewed in favour of $16 \mathrm{G}$ cannulas. At our institution, we routinely use IV cannulas to perform regional blocks using fascial "pop" techniques with satisfactory results.

The epidural catheter was placed at the time of administering the spinal anaesthetic for convenience. The TAP block cannulas were placed after the surgery to avoid them from posing a hindrance in the operative field. To compensate for the discrepancy in the timing of administration of the actual drug, the epidural administration of the drug was also done in the post-operative period.

The concentration of Bupivacaine injected was the same at $0.125 \%$ while the volume was $10 \mathrm{ml}$ in the epidural group and $20 \mathrm{ml}$ on each side i.e. $40 \mathrm{ml}$ in the TAP block group. The volume was meant to allow adequate spread of the local anaesthetic to cover roughly equivalent dermatomes. 
On analysis, both the groups were found to be comparable in their composition in terms of age, sex, height, weight, ASA Physical status, baseline heart rate, blood pressures and respiratory rate. In the first 8 and 16 hours, the VAS pain scores at rest and on coughing were comparable between the two groups.

However, the patients in the epidural group had better VAS scores at 24 and 48 hours with $91.7 \%$ and $86.1 \%$ of the patients in the epidural group pain free at 24 hours and 48 hours, respectively. In the TAP block group, the corresponding percentage of the patients being $51.5 \%$ and $45.5 \%$, respectively. The $\mathrm{P}$ values for this comparison were $<0.001$ and 0.004 , respectively.

The consumption of Paracetamol (first rescue analgesic) at 24 and 48 hours was comparable between the groups. However, the consumption of Tramadol (second rescue analgesic) was significantly higher in the TAP block group at the end of 24 hours as well as at the end of 48 hours. In the epidural group, $94.4 \%$ of the patients did not require Tramadol at the end of 24 hours as well as at the end of 48 hours. In comparison, only $63.6 \%$ and $60.6 \%$ of the patients in the TAP Block group did not require a second recue analgesic at the end of 24 and 48 hours, respectively. Further, in the TAP Block group $33.3 \%$ and $36.4 \%$ of the patients required $50 \mathrm{mg}$ Tramadol at the end of 24 and 48 hours, respectively. $3 \%$ of the patients required $100 \mathrm{mg}$ Tramadol at the end of 24 hours as well as 48 hours. In comparison, none of the patients in the Epidural group required 2 doses of Tramadol over the entire 48 hour period. This indicates that the Epidural group patients experienced better analgesia.

None of the patients in either group had any complications arising from the regional technique. Both groups of patients were haemodynamically stable during the 48 hours of follow-up.

\section{CONCLUSIONS}

Analgesia with epidural as well as with continuous TAP Block at $8^{\text {th }}$ hourly bolus dosing of $0.125 \%$ Bupivacaine in patients undergoing lower abdominal surgeries is comparable in the first 8 to 16 hours. However, the quality of analgesia provided by the TAP Block catheter is inferior to that provided by epidural catheters beyond 24 hours post-operative period.

\section{ACKNOWLEDGEMENT}

I am thankful to the Institution, the Department of Anaesthesiology, the patients who participated in the study, and the staff of operating theatres.

\section{REFERENCES}

[1] Yeager MP, Glass DD, Neff RK, et al. Epidural anaesthesia and analgesia in high-risk surgical patients. Anesthesiology 1987;66(6):729-36.
[2] Tuman KJ, McCarthy RJ, March RJ, et al. Effects of epidural anaesthesia and analgesia on coagulation and outcome after major vascular surgery. Anesthesia Analgesia 1991;73(6):696-704.

[3] McDonnell JG, O'Donnell B, Curly G. et al. The analgesic efficacy of transversus abdominis plane block after abdominal surgery: a prospective randomized controlled trial. Anesthesia Analgesia 2007;104(1):193-7.

[4] Abdallah FW, Halpern SH, Margarido CB. Transversus abdominis plane block for postoperative analgesia after Caesarean delivery performed under spinal anaesthesia? A systematic review and meta-analysis. British Journal of Anesthesiology 2012;109(5):67987.

[5] Carney J, McDonnell JG, Ochana A, et al. The transversus abdominis plane block provides effective postoperative analgesia in patients undergoing total abdominal hysterectomy. Anesthesia Analgesia 2008;107(6):205660.

[6] O'Donnell BD, McDonnell JG, McShane AJ. The transversus abdominis plane (TAP) block in open retropubic prostatectomy. Regional Anesthesia and Pain Medicine 2006;31(1):91.

[7] Charlton S, Cyna AM, Middleton P, et al. Perioperative transversus abdominis plane (TAP) blocks for analgesia after abdominal surgery. Cochrane Database Systematic Review 2010;8(12):CD007705.

[8] Rafi AN. Abdominal field block: a new approach via the lumbar triangle. Anaesthesia 2001;56(10):1024-6.

[9] Kearns RJ, Young SJ. Transversus abdominis plane blocks: a national survey of techniques used by UK obstetric anaesthetists. International Journal of Obstetric Anesthesia 2011;20(1):103-4.

[10] Tan TT, Teoh WHL, Woo DCM, et al. A randomised trial of the analgesic efficacy of ultrasound guided transversus abdominis plane block after caesarean delivery under general anaesthesia. European Journal of Anesthesiology 2012;29(2):88-94.

[11] Kanazi GE, Aouad MT, Abdallah FW, et al. The analgesic efficacy of subarachnoid morphine in comparison with ultrasound-guided transversus abdominis plane block after cesarean delivery: a randomized controlled trial. Anesthesia \& Analgesia 2010;111(2):475-81.

[12] Bollag L, Richebe P, Siaulys M, et al. Effect of transversus abdominis plane block with and without clonidine on post-cesarean delivery wound hyperalgesia and pain. Regional Anesthesia and Pain Medicine 2012;37(5):50814.

[13] Jankovic ZB, Pollard SG, Nachiappan MM. Continuous transversus abdominis plane block for renal transplant recipients. Anesthesia \& Analgesia 2009;109(5):171011.

[14] Kadam RV, Field JB. Ultrasound-guided continuous transverse abdominis plane block for abdominal surgery. Journal of Anesthesia and Clinical Pharmacology 2011;27(3):333-6.

[15] Kadam RV, Van Wijk RM, Moran JI, et al. Epidural versus continuous transversus abdominis plane catheter technique for postoperative analgesia after abdominal surgery. Anesthesia Intensive Care 2013;41(4):476-81. 
[16] Vandendriessche $H$, Hoydonckx $Y$, Pexsters A. Transversus abdomonis plane block (TAP) versus patient controlled epidural analgesia (PCEA) to treat post-cesarean section pain: a randomized, double-blind trial. Acta Anaesthesiologica Belgica 2010;61(2):107. 